\title{
Toward a Quantitative General Equilibrium Asset Pricing Model with Intangible Capital
}

\section{PRELIMINARY}

\author{
Hengjie Ai, Mariano Massimiliano Croce and $\mathrm{Kai} \mathrm{Li}^{1}$
}

January 2010

\begin{abstract}
In the US, the size of intangible investment is similar to that of physical investment. The risk premium for holding physical capital over intangible capital is comparable to the market equity premium. We present a quantitative general equilibrium asset pricing model with intangible capital whose predictions are consistent with key features of both macroeconomic quantity dynamics and stylized asset pricing facts. In particular, our model produces: 1) a high spread between the returns of tangible capital and intangible capital; 2) a high premium of the aggregate stock market over the risk-free interest rate; 3) a low and smooth risk-free interest rate; and 4) dynamics for macroeconomic quantities consistent with US data. Our model rationalizes about $75 \%$ of the observed difference in the average return of book-to-market sorted portfolios.
\end{abstract}

\footnotetext{
${ }^{1}$ Hengjie Ai is an assistant professor at the Fuqua School of Business, Duke University. Mariano Massimiliano Croce is an assistant professor at the UNC Kenan-Flagler Business School. Kai Li is at the economics department of Duke University.
} 


\section{Introduction}

Investment in intangible capital is large. Focusing on post-war US data, Corrado, Hulten, and Sichel (2005) and Corrado, Hulten, and Sichel (2006) show that investment in intangible capital is similar in magnitude to physical investment. At the same time, the average return of intangible capital is significantly lower than that of physical capital. Historically, stocks with high book-to-market ratio (value stocks) earn a higher average return than those with low book-to-market ratio (growth stocks) by about 5\% per year (value premium). One of the defining features of intangible capital is that its value should be embodied in the market valuation even though it is typically excluded from the book value of the firm. Given this consideration, value firms are tangible-capital intensive, while growth firms are intangiblecapital intensive. Interpreted in this way, the empirical evidence on value premium implies that the average spread between the return of physical and intangible capital is comparable the aggregate stock market equity premium.

The goal of this paper is to propose a quantitative general equilibrium asset pricing model consistent with the key features of macroeconomic quantity dynamics and asset returns, in particular, the difference in the returns to physical and intangible capital. Our model generates a high equity premium (4.54\% per year for the market return) with moderate risk aversion (10), and a low and smooth risk-free interest rate. Our results are comparable to those obtained by the standard real business cycle (RBC) models in term of the second moments of aggregate consumption and investment growth rates. Furthermore, the expected annual return on intangible capital is $4.29 \%$ lower than that on tangible assets, about $75 \%$ of the observed value premium in the data.

We follow Ai (2009b) and model intangible capital as investment options. In particular, physical capital must be produced by combining physical investment (equipment, machines, hardwares) and intangible capital (ideas, blueprints, business plans, softwares). Investment options differ by their quality, meaning that high quality investment options require a lower amount of physical investment to create a unit of physical capital. In equilibrium, more efficient investment options are implemented first. This implies that on the margin, an additional unit of physical capital is produced using options with lower quality and costs more physical investment goods. This mechanism endogenously generates variations in the price of tangible capital similar to those obtained with capital adjustment cost, making tangible capital more risky than intangible capital.

We make two important modifications to the Ai (2009b) model. First, we adopt recursive

preferences and an aggregate productivity process with long-run uncertainty as in Croce 
(2008). The predictions of our model are supported by empirical evidence on the crosssection of equity returns. For example, Bansal, Dittmar, and Lundblad (2005), ?), and Kiku (2006) document that value stocks have higher exposure to long-run consumption risk than growth stocks. Our production-based model rationalizes these empirical findings, as in the equilibrium tangible capital is more sensitive to variations in the predictable component of consumption growth than intangible capital.

Second, our model features overlapping vintages of physical capital. Focusing on US micro-data, we provide novel empirical evidence showing that new investment is less sensitive to aggregate productivity shocks than physical assets of older vintages. We model this fact by assuming that new investment units respond to aggregate shocks with a one-period lag. By incorporating this feature, we generate a crucial asymmetry in the optimal response of investment to unexpected contemporaneous productivity shocks (short-run shocks) and news about future productivity (long-run shocks).

In our set-up, the elasticity of substitution between tangible investment and intangible capital is high, implying that adjusting tangible capital is not costly. Consequently, investment responds strongly to short-run shocks as it does in standard real business cycle models. The response of investment to long-run shocks, however, is sluggish for two reasons. First, good long-run news do not immediately increase output, as they only anticipate higher productivity in the future. Second, since the response of the productivity of new vintages is lagged, the agent finds it optimal to delay investment. At the equilibrium, after a long-run shock, asset prices respond immediately and sharply while quantities do not. This feature of the model is novel and allows us to reproduce the high equity and value premium observed in the data, while maintaining the appealing features of the real business cycle models on the quantity side.

Our paper is closely related to the literature on asset pricing in production economies that dates back at least to Brock and Mirman (1972). Rouwenhorst (1995) is among the first ones to recognize the difficulty to resolve the equity premium puzzle (Mehra and Prescott (1985)) in production economies even with extreme risk aversions. Recent attacks on this issue can be broadly classified into three classes: habit based models (for example, Jermann (1998) and Boldrin, Christiano, and Fisher (2001)), long-run risk based models (for example Lochstoer and Kaltenbrunner (2008), Croce (2008), Campanale, Castro, and Clementi (2008) and Ai (2009a)), and rare disaster based models (for example, Gourio (2009)). Our work differs from the above papers in two significant ways. First, our model addresses both the equity premium and the spread between tangible and intangible capital simultaneously, while the aforementioned papers focus only on equity premium. Second, the papers listed 
above typically rely on capital adjustment costs or other frictions in investment as the only channel to generate variations in the price of physical capital. There is typically substantial tension among the intensity of the adjustment costs, the volatility of the price of capital and the volatility of risk-free interest rate. Strong adjustment costs, while necessary to generate a sizeable equity premium, are often associated with either a counterfactually low volatility of investment or a counterfatucally high volatility of the risk-free interest rate. Our model produces a low volatility of risk-free interest rate, a significant volatility of stock market returns, and a high volatility of investment as in the data.

There is an extensive financial literature that emphasizes the importance of the riskiness of options versus assets in place in understanding the cross section of equity returns (for example, Berk, Green, and Naik (1999), Gomes, Kogan, and Zhang (2003), Carlson, Fisher, and Giammarino (2004), Cooper (2006), and Panageas and Yu (2006)). Our model is more related to recent studies suggesting that investment options are less risky than physical capital, as in Zhang (2005), Ai and Kiku (2009), and Papanikolaou (2008). Kogan and Papanikolaou (2009) develops a measure of option intensity of firms and provides a directly empirical evidence on option being less risky than physical assets. Our work complements this literature by interpreting investment options as intangible capital and studying its implications in a fully specified macroeconomic general equilibrium model.

Adopting the empirical evidence on value premium as a discipline to study intangible capital in quantitative general equilibrium models is relatively new. Jovanovic (2008) also models intangible capital as investment options in general equilibrium. McGrattan and Prescott (2005), McGrattan and Prescott (2009b) and McGrattan and Prescott (2009a) also emphasize the importance of intangible capital in understanding economic fluctuation in the 1990's and the valuation of asset returns. The above models do not address the difference in the return of tangible can intangible capital as we do in this paper.

The rest of the paper is organized as follows. We present the model and some analytical results in Section I and II. In Section III of the paper, we document the empirical facts on the differential exposure to aggregate risk of young and old firms. We provide our results in Section IV of the paper. Section V concludes. Proofs of the theorems, and robustness analysis of the empirical results can be found in the appendix of the paper. 


\section{Model Setup}

\section{A Preferences}

Time is discrete and infinite, $t=1,2,3, \cdots$. The representative agent has Kreps-Porteus preferences as in Epstein and Zin (1989):

$$
V_{t}=\left\{(1-\beta) u\left(C_{t}, N_{t}\right)^{1-\frac{1}{\psi}}+\beta\left(E_{t}\left[V_{t+1}^{1-\gamma}\right]\right)^{\frac{1-1 / \psi}{1-\gamma}}\right\}^{\frac{1}{1-1 / \psi}}
$$

where $C_{t}$ and $N_{t}$ denote, respectively, the total consumption and total hours worked at date $t$. For simplicity, we assume an inelastic labor supply, normalize $N_{t}=1$, and set $u\left(C_{t}, N_{t}\right)=C_{t}$.

\section{B Technology}

Consumption goods are perishable and are produced by production units of overlapping generations. Production units created at time $\tau$ are called generation- $\tau$ production units and begin operation at time $\tau+1$. Each generation- $\tau$ production unit uses labor, $n^{\tau}$, as the only input of production. For $t \geq \tau+1$, let $A_{t}^{\tau}$ denote the time $t$ productivity level common to all the production units belonging to generation- $\tau$. The total output of a generation- $\tau$ production unit at time $t, y_{t}^{\tau}$, is given by:

$$
y_{t}^{\tau}=\left(A_{t}^{\tau} n_{t}^{\tau}\right)^{1-\alpha}, \quad \forall t \geq \tau+1
$$

In each period, a production unit dies with probability $\delta_{K}$ after its production activity is completed. We assume that the death shocks are i.i.d. among all production units, therefore a fraction $1-\delta_{K}$ of production units survives to the next period. Let $M_{t}$ denote the total measure of generation $t$ production units created in period $t$, then for all $j \geq 1$, the total measure of generation $t$ production units alive at period $t+j$ is $\left(1-\delta_{K}\right)^{j-1} M_{t}$. Since all production units belonging to the same generation have identical output, total output at time $t, Y_{t}$, is given by:

$$
Y_{t}=\sum_{\tau=0}^{t-1}\left(1-\delta_{K}\right)^{t-\tau-1} M_{\tau} y_{t}^{\tau}
$$

Let $I_{t}$ denote the total investment in physical capital, and $J_{t}$ denote the total investment 
in intangible capital in the economy. The resource constraint of the economy is written as:

$$
C_{t}+I_{t}+J_{t}=Y_{t}
$$

\section{Productivity}

We first specify the economy-wide productivity process, denoted by $A_{t}$, whose growth rate evolves as follows:

$$
\begin{aligned}
\frac{A_{t+1}}{A_{t}} & =e^{\mu+x_{t}+\sigma_{a} \varepsilon_{a, t+1}} \\
x_{t+1} & =\rho x_{t}+\sigma_{x} \varepsilon_{x, t+1} \\
{\left[\begin{array}{c}
\varepsilon_{a, t+1} \\
\varepsilon_{x, t+1}
\end{array}\right] } & \sim \text { i.i.d.N }\left(\left[\begin{array}{l}
0 \\
0
\end{array}\right],\left[\begin{array}{ll}
1 & 0 \\
0 & 1
\end{array}\right]\right), \quad t=0,1,2, \cdots .
\end{aligned}
$$

This specification follows Croce (2008) and captures long-run productivity risk. We further assume that production units are not exposed to aggregate risk during the first period of their lives. Specifically, the growth rate of the productivity of generation- $t$ production units is given by:

$$
\frac{A_{t+j+1}^{t}}{A_{t+j}^{t}}=e^{\mu+\phi\left(x_{t}+\sigma_{a} \varepsilon_{a, t+1}\right)},
$$

where $\phi=1$ for $j=1,2,3, \ldots$, and for $j=0$ we assume $\phi<1$. We also set $A_{t}^{t}=A_{t}$ in order to ensure that new production units are on average as productive as older ones. ${ }^{2}$

Under the above specification, production units of all generations have the same unconditional expected growth rate. In the first period of its life, a new born production unit is less exposed to aggregate shocks. From the second period on, its productivity grows at the same rate of all other production units of older generations. This feature of our model captures the empirical fact that exposure to aggregate productivity uncertainty is increasing in firms' age, as documented in Section III.

\section{Dynamics of Tangible and Intangible Capital}

We model tangible capital as the stock of productive assets in the economy, i.e., the total amount of production units in our setup. Although our model features overlapping generations of production units with different productivity levels, our specification of the productivity processes allows a simple aggregation result summarized by the following proposition.

\footnotetext{
${ }^{2}$ Generation- $t$ production units are not active until period $t+1$, therefore the level of $A_{t}^{t}$ does not affect the total production of the economy in period $t$.
} 
Proposition 1 (Aggregation of Production Units):

The aggregate production is given by:

$$
Y_{t}=K_{t}^{\alpha}\left(A_{t} N_{t}\right)^{1-\alpha}
$$

where $K_{t}$ is the effective measure of production units in the economy, and can be constructed in a recursive fashion:

$$
K_{t+1}=\left(1-\delta_{K}\right) K_{t}+\varpi_{t+1} M_{t}
$$

where

$$
\varpi_{t+1}=e^{-\frac{1-\alpha}{\alpha}\left(x_{t}+\sigma_{a} \varepsilon_{a, t+1}\right)}
$$

Proof. See Appendix

Intuitively, $K_{t}$ aggregates production units of different generations. The differences in productivity across generations is taken into account by the sequence of weights $\left\{\varpi_{j+1}\right\}_{j=0}^{t}$.

We model intangible capital by investment options. The total measure of investment options at period $t$ is denoted $S_{t}$. We assume that one investment option create exactly one production unit if implemented; therefore, the total measure of investment options used in period $t$ is equal to the total measure of new production units constructed, $M_{t}$. If not exercised, an investment option vanishes with probability $\delta_{S}$ at the end of the period. The decision to exercise an investment option is irreversible. These assumptions imply that the amount of unexercised investment options at the end of period $t$ is $\left(S_{t}-M_{t}\right)\left(1-\delta_{S}\right)$. We assume that one unit of consumption good can be used to produce one unit of investment option. Therefore, the total measure of new investment options created at time $t$ is $J_{t}$. Consequently, the law of motion of the total measure of investment options can be written as

$$
S_{t+1}=\left(S_{t}-M_{t}\right)\left(1-\delta_{S}\right)+J_{t}
$$

\section{E Technology for New Production Units}

A new production unit can be created by exercising an investment option. Investment options differ by their quality. The quality of an investment option, denoted by $\theta$, is drawn from a continuous density $\phi$ at the beginning of each period. The random draw of $\theta$ is i.i.d. among investment options and over time. The owner of an investment option decides whether to implement it immediately after the revelation of its quality. If implemented, an investment option with quality $\theta$ requires $\frac{1}{\theta}$ units of investment goods to create one production unit. If not immediately implemented, the option vanishes with probability $\delta_{S}$ at the 
end of the period. Each surviving investment option obtains another independent draw of $\theta$ in the next period from the same density $\phi$. Given $\phi$, hence, the total measure of production units created in period $t, M_{t}$, depends only on the total amount of physical investment, $I_{t}$, and the total amount of intangible capital stock, $S_{t}$. We denote this relationship with a function $G$ such that $M_{t}=G\left(I_{t}, S_{t}\right)$. In efficient allocations, investment options of higher quality are implemented first. Consequently, the function $G$ can be written as the solution to the following optimization problem:

$$
\begin{gathered}
G(I, S)=\max _{\theta^{*}}\left\{S \times \int_{\theta^{*}} \phi(\theta) d \theta\right\} \\
\text { subject to } S \times \int_{\theta^{*}} \phi(\theta) d \theta \leq I .
\end{gathered}
$$

Using the $G(I, S)$ function defined above, the law of motion of tangible and intangible can be written as:

$$
\begin{aligned}
K_{t+1} & =\left(1-\delta_{K}\right) K_{t}+\varpi_{t+1} G\left(I_{t}, S_{t}\right) \\
S_{t+1} & =\left[S_{t}-G\left(I_{t}, S_{t}\right)\right]\left(1-\delta_{S}\right)+J_{t} .
\end{aligned}
$$

\section{Model Solution}

\section{A The Social Planner's Problem}

We consider a competitive equilibrium with complete markets in which claims to production units and investment options are traded. The competitive equilibrium prices and quantities can be constructed from the solution to the social planner's problem. Let $z=[K, S, x, A]$ be the vector of state variables, the social planner's problem can be written as a dynamic 
programming problem:

$$
\begin{aligned}
V(z) & =\left\{(1-\beta) C^{1-\frac{1}{\psi}}+\beta\left(E\left[V\left(z^{\prime}\right)^{1-\gamma} \mid z\right]\right)^{\frac{1-1 / \psi}{1-\gamma}}\right\}, \\
\text { subject to } & : C+I+J=A^{1-\alpha} K^{\alpha}, \\
K^{\prime} & =K\left(1-\delta_{K}\right)+\varpi^{\prime} G(I, S), \\
S^{\prime} & =[S-G(I, S)]\left(1-\delta_{S}\right)+J, \\
C, I & \geq 0 . \\
A^{\prime} & =A e^{\mu+x+\sigma_{a} \varepsilon_{a}^{\prime}} \\
x^{\prime} & =\rho x+\sigma_{x} \varepsilon_{x}^{\prime} \\
\varpi^{\prime} & =e^{-\frac{1-\alpha}{\alpha}\left[x+\sigma_{a} \varepsilon_{a}^{\prime}\right]} \\
{\left[\begin{array}{c}
\varepsilon_{a}^{\prime} \\
\varepsilon_{x}^{\prime}
\end{array}\right] } & \sim \text { i.i.d.N }\left(\left[\begin{array}{l}
0 \\
0
\end{array}\right],\left[\begin{array}{ll}
1 & 0 \\
0 & 1
\end{array}\right]\right) .
\end{aligned}
$$

Although the constraint $S^{\prime}=[S-G(I, S)]\left(1-\delta_{S}\right)+J$ is nonconvex, Ai (2009b) shows that the second welfare theorem holds in this kind of environment as well. ${ }^{3}$ This allows us to construct equilibrium prices from the optimal policy functions of the above problem in a recursive fashion. In the next subsection, we derive the asset pricing implications of the model by studying the first order conditions and the envelope conditions of the social planner's problem.

\section{B Asset Prices}

Let $C(z), I(z), J(z)$ denote the policy functions of the dynamic programming problem. The stochastic discount factor is:

$$
\Lambda\left(z, z^{\prime}\right)=\beta\left(\frac{C\left(z^{\prime}\right)}{C(z)}\right)^{-\frac{1}{\psi}}\left[\frac{V\left(z^{\prime}\right)}{\left(E\left[V\left(z^{\prime}\right)^{1-\gamma} \mid z\right]\right)^{\frac{1}{1-\gamma}}}\right]^{\frac{1}{\psi}-\gamma} .
$$

\footnotetext{
${ }^{3}$ Although Ai (2009b) works with time additive preferences and does not have overlapping vintages of capital, his proof can be extended to our set-up.
} 
Let $q_{K}(z)$ and $q_{S}(z)$ denote, respectively, the price of an additional unit of aggregate physical and intangible capital. We can define $q_{K}(z)$ and $q_{S}(z)$ recursively as follows:

$$
q_{K}(z)=E\left[\Lambda\left(z, z^{\prime}\right)\left\{\alpha\left(\frac{A^{\prime}}{K^{\prime}}\right)^{1-\alpha}+\left(1-\delta_{K}\right) q_{K}\left(z^{\prime}\right)\right\} \mid z\right]
$$

and

$$
q_{S}(z)=E\left[\Lambda\left(z, z^{\prime}\right)\left\{\frac{G_{S}\left(I\left(z^{\prime}\right), S^{\prime}\right)}{G_{I}\left(I\left(z^{\prime}\right), S^{\prime}\right)}+\left(1-\delta_{K}\right) q_{S}\left(z^{\prime}\right)\right\} \mid z\right]
$$

Note that the term $\alpha\left(\frac{A^{\prime}}{K^{\prime}}\right)^{1-\alpha}$ in equation (11) is the marginal product of physical capital. One unit of physical capital pays $\alpha\left(\frac{A^{\prime}}{K^{\prime}}\right)^{1-\alpha}$ in the next period, and becomes $\left(1-\delta_{K}\right)$ unit of physical capital after depreciation. Similarly, the term $\frac{G_{S}(I, S)}{G_{I}(I, S)}$ in Equation (12) is the marginal product of intangible capital. To see this, note that $G_{S}(I, S)$ is the amount of new production units that can be produced by an additional unit of investment option, and $\frac{1}{G_{I}(I, S)}$ is the relative price of an additional unit of physical capital in terms of output. The ratio $\frac{G_{S}(I, S)}{G_{I}(I, S)}$ can also be interpreted as the option payoff.

It is also convenient to define $p_{K}(z)$ as the cum-dividend value of one unit of physical capital, and $p_{S}(z)$ as the value of one unit of investment option before the quality of the option is revealed and the option exercise decision is made:

$$
\begin{aligned}
& p_{K}(z)=\alpha\left(\frac{A}{K}\right)^{1-\alpha}+\left(1-\delta_{K}\right) q_{K}(z), \\
& p_{S}(z)=\frac{G_{S}(I(z), S)}{G_{I}(I(z), S)}+\left(1-\delta_{K}\right) q_{S}(z) .
\end{aligned}
$$

Using this notation, the first order conditions of the social planner's problem allow us to obtain the following proposition.

Proposition 2 (Equilibrium Conditions)

The optimal solution to the social planner's problem satisfies the following conditions:

$$
\begin{gathered}
E\left[\Lambda\left(z, z^{\prime}\right) \varpi^{\prime} p_{K}\left(z^{\prime}\right) \mid z\right]=\frac{1}{G_{I}(I, S)}+\left(1-\delta_{S}\right) q_{S}(z) \\
q_{S}(z)=1 .
\end{gathered}
$$

Furthermore, an investment option is implemented if and only its quality is above $\theta^{*}(z)$, 
where $\theta^{*}(z)$ is given by:

$$
\theta^{*}(z)=G_{I}(I(z), S)
$$

Proof. See Ai (2009b).

To understand the conditions above, note that the left hand side of equation (13) is the marginal benefit of one unit of newly created physical capital. The value of one unit of physical capital in the next period is $p_{K}\left(z^{\prime}\right) ; \varpi^{\prime}$ adjusts for the difference in productivity among newly created physical capital and existing production units. The right hand side of equation (13) is the marginal cost of a new production unit. Since the creation of a production unit requires $\frac{1}{\theta}$ investment goods if it involves an idea with quality $\theta$, by equation (15) at the margin an additional production unit costs $\frac{1}{\theta^{*}(z)}=\frac{1}{G_{I}(I(z), S)}$ investment goods. Note that a new production unit also requires implementation of an investment option. After taking into account the mortality probability of non-implemented ideas, the opportunity of cost of an investment option is $\left(1-\delta_{S}\right) q_{S}(z)$.

Equation (14) implies that the value of an unimplemented idea is always 1. This is due to the production technology of new investment options. Since one unit of consumption good can always be transformed into one unit of investment option (see equation (2) and (9)), the relative price of intangible capital in terms of the current period consumption numeraire is always 1 . This is analogous to neoclassical growth model without capital adjustment cost.

Using the above proposition, the realized return on physical capital and intangible capital, denoted $r_{K}$ and $r_{S}$, respectively, can be written as:

$$
r_{K}\left(z, z^{\prime}\right)=\frac{\alpha\left(\frac{A^{\prime}}{K^{\prime}}\right)^{1-\alpha}+\left(1-\delta_{K}\right) q_{K}\left(z^{\prime}\right)}{q_{K}(z)},
$$

and

$$
r_{S}\left(z, z^{\prime}\right)=\frac{\frac{G_{S}\left(I\left(z^{\prime}\right), S^{\prime}\right)}{G_{I}\left(I\left(z^{\prime}\right), S^{\prime}\right)}+\left(1-\delta_{S}\right) q_{S}\left(z^{\prime}\right)}{q_{S}(z)}=\frac{G_{S}\left(I\left(z^{\prime}\right), S^{\prime}\right)}{G_{I}\left(I\left(z^{\prime}\right), S^{\prime}\right)}+\left(1-\delta_{S}\right) .4
$$

For later reference, we note that equation (11) and (12) can be iterated forward and expressed as:

$$
q_{K}\left(z_{t}\right)=\sum_{j=1}^{\infty}\left(1-\delta_{K}\right)^{j} E_{t}\left[\left(\prod_{s=0}^{j} \Lambda\left(z_{t+s}, z_{t+s+1}\right)\right) \alpha A_{t+j} K_{t+j}^{\alpha-1}\right],
$$

\footnotetext{
${ }^{4}$ Note $r_{S}\left(z, z^{\prime}\right)$ is the realized return of an investment option before the quality of the investment option is revealed. In other words, $r_{S}\left(z, z^{\prime}\right)$ does not account for the random draw of the quality of the option. Since the realization of the quality of an investment option is idiosyncratic, the risk premium of an investment option is completely determined by $r_{S}\left(z, z^{\prime}\right)$.
} 


$$
q_{S}\left(z_{t}\right)=\sum_{j=1}^{\infty}\left(1-\delta_{S}\right)^{j} E_{t}\left[\left(\prod_{s=0}^{j} \Lambda\left(z_{t+s}, z_{t+s+1}\right)\right) \frac{G_{S}\left(I\left(z_{t+j}\right), S_{t+j}\right)}{G_{I}\left(I\left(z_{t+j}\right), S_{t+j}\right)}\right] .
$$

According to equation (18), the price of an average production unit is simply the present value of the future stream of marginal product of physical capital. This implies that the model needs to produce enough variations in the marginal product of tangible capital in order to generate high risk exposure for physical capital.

Equation (19) implies that the price of intangibles has to equal the present value of all its future option payoffs. Since the supply of new investment options is perfectly flexible, the price of intangibles is constant, i.e. $q_{S}(z)=1$. At the equilibrium, hence, only the quantity of intangible investment $J_{t}$ responds to productivity shocks.

\section{Firms' Exposure to Aggregate Risks}

In our economy, new production units are less sensitive to aggregate productivity shocks. In this section we provide empirical evidence that supports this feature of the model. A production unit in our model should be interpreted as any investment project generating cash flows. Because it is difficult to identify productivity of individual projects within firms, we adopt an indirect approach. We hypothesize that younger firms have more new-vintage projects than older firms, and show that the productivity growth rate of younger firms has less exposure to aggregate productivity risk.

In particular, we assume that the production function at the firm level is Cobb-Douglas:

$$
y_{i t}=a_{i, t} k_{i, t}^{\alpha_{1}} n_{i, t}^{\alpha_{2}} \text {, }
$$

where $k_{i, t}$ and $n_{i, t}$ are, respectively, the capital and labor inputs of firm $i$, and $a_{i, t}$ is the firmspecific productivity level at time $t .^{5}$ In the empirical analysis, we allow for $\alpha_{1}+\alpha_{2} \neq 1 .^{6}$

Consistent with the notation in our model, we denote aggregate productivity in the economy by $A_{t}$. Our analysis shows that $\operatorname{Cov}\left[\ln \left(a_{i, t+1}\right)-\ln \left(a_{i, t}\right), \ln \left(A_{t+1}\right)-\ln \left(A_{t}\right)\right]$ is increasing with firms' age.

Since it is also reasonable to conjecture that smaller firms have more new investment

\footnotetext{
${ }^{5}$ This specification is not inconsistent with our model even though we assume that production units use labor as the only input. Under the assumption of constant return to scale, firm size is undetermined in our model. In the data, a firm can be viewed as a collection of production units (projects), and the observed capital stock, $k_{i, t}$, can be interpreted as the measure of production units owned by the firm.

${ }^{6}$ Restricting the production technology to be constant return to scale at the firm level, that is $\alpha_{1}+\alpha_{2}=1$, does not significantly affect our results.
} 
projects than larger firms, we present further empirical evidence suggesting that small firms are indeed less exposed to aggregate productivity shocks than large firms. These results are reported in Appendix B.

\section{A Data}

We consider all public traded companies on US and Canadian stock exchanges in the COMPUSTAT North America database for the period of 1950 - 2006. Output, or value added of a firm, $y_{i, t}$, is calculated as sales minus the cost of goods sold and is deflated by the aggregate GDP deflator from NIPA. We measure the capital stock $k_{i, t}$ as total value of assets minus current assets. This allows us to exclude cash and other liquid assets that may not be an appropriate component of physical capital. We use the number of employees in a firm to proxy for $n_{i, t}$ as total hours worked are not available. Since the database does not provide explicit indicators for firms' age, we use the number of years for which a firm appeared in COMPUSTAT as a proxy. This is consistent with previous literature. We use the multifactor productivity index for the private non-farm business sector from the Bureau of Labor Statistics $(B L S)$ for the measure of aggregate productivity $A_{t}$.

Table 1 presents the summary statistics for firms of six age groups. As documented in earlier literature, firm size and age are highly correlated. Although, young firms are small in terms of total output, capital stock, and number of employees, overall they accounts for a large fraction of our observations in the sample.

(INSERT TABLE 1 HERE)

\section{B Empirical Strategy and Results}

We follow a two step procedure. In the first step, we calculate the log-level firm productivity, denoted by $\ln a_{i, t}$, as the residue of the regression implied by equation (20):

$$
\ln y_{i, t}=\alpha_{1} \ln k_{i, t}+\alpha_{2} \ln n_{i, t}+\ln a_{i, t} .
$$

In the second step, we regress individual firm's productivity growth rates, $\Delta \ln a_{i, t}$, on aggregate productivity growth, $\Delta \ln A_{t}:{ }^{7}$

$$
\Delta \ln a_{i, t}=\xi_{0}+\xi_{0, i}+\xi_{1} \Delta \ln A_{t}+\xi_{2} A G E_{i, t}+\xi_{3} A G E_{i, t} * \Delta \ln A_{t}+\varepsilon_{i, t} .
$$

\footnotetext{
${ }^{7}$ In expression (22), $\Delta \ln a_{i, t}=\ln a_{i, t}-\ln a_{i, t-1}$ and $\Delta \ln A_{t}=\ln A_{t}-\ln A_{t-1}$.
} 
We allow for a firm fixed effect in productivity growth rate $\xi_{0, i}$. The coefficient $\xi_{3}$ captures the age effect on firms' sensitivity to aggregate productivity growth.

Table 2 reports our results. The first stage refers to the estimation of equation (21). We try two different specifications, i.e. with and without the fix effect in the first stage regression, and obtain very similar estimation results. The capital share $\alpha_{1}$ ranges from 0.36 to 0.39 , and is consistent with macro data. The sum of capital share $\alpha_{1}$ and labor share $\alpha_{2}$ is consistently smaller than 1 , implying that the production function has decreasing return to scale. This result is consistent with previous studies (see among others Dhawan (2001)).

In the second stage, the estimate of $\xi_{3}$ on the cross term $A G E_{i t} * \Delta \log A_{t}$ is positive and statistically significant, meaning that firms' exposure to aggregate productivity risk is increasing in firms' age. We present several robustness checks in Appendix B, including a different proxy for firms' age, and corrections for sample selection bias based on Heckman's two-stage procedure. In all these experiments, we find that both younger and smaller firms have significantly less exposure to the aggregate productivity risk.

(INSERT TABLE 2 HERE)

We consider the empirical evidence presented in this section as a solid motivation for our parsimonious model specification.

\section{Quantitative Implications of the Model}

In this section, we calibrate our model and evaluate its ability to replicate key moments of both macroeconomic quantities and asset returns. The model is calibrated at annual frequency and all moments are annual.

\section{A Parameter Values}

There are three major ingredients in our model: overlapping generations of vintage capital, long-run productivity risk, and intangible capital. In order to understand the importance of each ingredient, we compare four different calibrations. Our Benchmark model has all three ingredients according to our preferred calibration. Model 1 does not have vintage capital, but maintains all other features of the Benchmark model, namely, long-run productivity risk and intangible capital. In Model 2, we further switch off fluctuations in long-run productivity growth. In particular, model 2 incorporates intangible capital, but imposes that production units of all generations have the same productivity (by setting $\phi=1$ ), 
and assumes no long-run productivity risk (by setting $\sigma_{x}=0$ ). Finally, we consider the case without intangible capital in Model 3. Essentially, Model 3 is the neoclassical growth model with recursive preferences and i.i.d productivity growth rates. The details of the four models are summarized in the following table:

\begin{tabular}{lllll}
\hline \hline & BENCHMARK & Model 1 & Model 2 & Model 3 \\
\hline Vintage Capital & Yes $(\phi=0)$ & No $(\phi=1)$ & No $(\phi=1)$ & No $(\phi=1)$ \\
Long-run Productvity Risk & Yes $\left(\sigma_{x} \neq 0\right)$ & Yes $\left(\sigma_{x} \neq 0\right)$ & No $\left(\sigma_{x}=0\right)$ & No $\left(\sigma_{x}=0\right)$ \\
Intangible Capital & Yes & Yes & Yes & No \\
Recursive Preference & Yes & Yes & Yes & Yes \\
\hline \hline
\end{tabular}

Parameters of the model can be divided into two groups. The first group of parameters is chosen independently of the moments of macroeconomic quantities or asset returns that we are interested in. They can be pinned down either from micro evidence, or point estimates in the empirical literature, or by following well-established conventions in the previous literature. These parameters are identical across all four calibrations. The second set of parameters are calibrated to match the relevant steady-state moments in the data.

The first group of parameters include risk aversion, $\gamma$, intertemporal elasticity of substitution, $\psi$, capital share, $\alpha$, depreciation rates, $\delta_{K}$ and $\delta_{S}$, average grow rate of the economy, $\mu$, and the first-order autocorrelation of the predictable component in productivity growth, $\rho$. We choose risk aversion and intertemporal elasticity of substitution in line with the long-run risk literature. In particular, we set $\gamma=10$, and $\psi=2$. We choose the capital share $\alpha=0.3$, and the annual depreciation rate of physical capital $\delta_{K}=10 \%$, consistent with the real business cycle literature (Kydland and Prescott (1982)). We choose the same rate of depreciation for intangible capital: $\delta_{S}=10 \%$ per year. We calibrate $\mu=2 \%$ per year, which is consistent with the average annual growth rate of the US economy in the post war period. We set $\rho=0.93$, which is the point estimate obtained in Croce (2008).

The second group of parameters includes the discount factor, $\beta$, the standard deviation of the persistent component of productivity growth, $\sigma_{x}$, the short-run shock volatility, $\sigma_{a}$ and parameters of the aggregator $G(I, S)$. In all calibrations, we set the discount factor $\beta$ to match the level of the risk-free interest rate in the data if possible. An exception is Model 3, which does not have enough parameters to match both the level of the risk-free rate and the consumption-tangible investment ratio. We choose $\beta$ in Model 3 to match the consumption-tangible investment ratio but not the level of the risk-free rate. We set $\sigma_{a}$ and $\sigma_{x}$ in both the Benchmark model and Model 1 in order to approximately match the 
standard deviation and the first-order autocorrelation of the annual growth rate of measured output. The definition of measured output can be found in Appendix C. In both Model 2 and Model 3, we impose $\sigma_{x}=0$ and set $\sigma_{a}$ in order to match the standard deviation of the annual growth rate of measured output.

We choose the aggregator $G(I, S)$ to be of the CES form:

$$
G(I, S)=\left(\nu I^{1-\frac{1}{\eta}}+(1-\nu) S^{1-\frac{1}{\eta}}\right)^{\frac{1}{1-1 / \eta}}
$$

The aggregator $G$ is described by two parameters, $\nu$ and $\eta$, chosen to approximately match the steady-state consumption-tangible investment ratio and the consumption-intangible investment ratio across all models, if possible. ${ }^{8}$ The calibrated parameter values are summarized in Table 3 and the steady-state moments used to calibrate the parameters are displayed in Table 4.

(INSERT TABLE 3 HERE)

\section{(INSERT TABLE 4 HERE)}

We solve the model using a second-order local approximation around the stochastic steady-state. $^{9}$ We also numerically solved the models using a finite element-based global approximation method to check the accuracy of the local approximation method. Overall, the two numerical solutions produce very similar results.

\section{B Quantity Dynamics}

In this section, we show that all four models produce similar macroeconomic quantity dynamics, and that our Benchmark model improves slightly upon the RBC model (Model 3 ) in several dimensions. In this sense, our model inherits the success of the RBC models on the quantity side of the economy.

The quantity dynamics produced by our calibrations are shown in the first panel of Table 5. All four calibrations produce a small volatility of consumption growth and a high volatility of tangible investment growth, consistent with the data. Recall that Model 3 is essentially the standard RBC model with recursive preferences. We know from Tallarini

\footnotetext{
${ }^{8}$ Model 3 does not have intangible capital, so $E[I / J]$ is not defined. In Model 2, the parameter $\eta$ has just minor effects on the stochastic steady state, therefore it is not possible to match both $E[C / I]$ and $E[I / J]$ simultaneously. In Model 2, we follow the RBC literature and set $\nu$ to match the consumption-physical investment ratio observed in the data.

${ }^{9}$ We thank the authors of the dynare++ package for kindly providing us the updated source code.
} 
(2000) that the risk aversion parameter of the recursive preference has little effect on the quantity dynamics. Therefore, on the quantity side, the model behaves just like the standard RBC model with CRRA preference where $\gamma=\frac{1}{\psi}=0.5$. Table 7 shows that the second moments generated by Model 3 are consistent with those in Kydland and Prescott (1982). In particular, the model produces a small standard deviation of consumption, $2.47 \%$ per year, and a standard deviation of investment about five times larger: $12.61 \%$ per year.

By comparing Model 2 and 3, we see that adding intangible capital to the standard $\mathrm{RBC}$ model reduces the volatility of physical investment growth. This is due to the fact that the aggregator $G$ affects the model similarly to an adjustment cost function. In order to generate a high volatility of investment, hence, the curvature of $G(I, S)$ needs to be low, or, equivalently, the elasticity of substitution between $I$ and $S, \eta$, needs to be sufficiently high. This is exactly what we have across all our calibrations.

Adding long-run productivity risk provides an additional source of variations in the expected return of physical capital. By comparing Model 1 and 2, we see that long-run risk increases the volatility of the growth rate of physical investment. A similar positive effect is also produced by the introduction of different vintages of capital. As a result, our Benchmark model produces a $12.48 \%$ annual volatility of investment growth, similar to Model 1.

Another interesting dimension to study is the persistence of the the quantities' growth rates. In Model 2 and 3, both output and consumption are autocorrelated, even if productivity growth is not. This result is generated by the persistent fluctuations of our endogenous state variables, $K$ and $S$ (as in Lochstoer and Kaltenbrunner (2008)). The persistence generated in these two models, however, is smaller than in the data. Adding long-run productivity risk increases the autocorrelation of both consumption and output growth rate (Croce (2008)). Since both the Benchmark model and Model 1 feature long-run productivity uncertainty, they produce a higher autocorrelation both in output growth (Table 4) and consumption growth (Table 5) than Model 2 and 3. We consider this feature as an improvement upon Model 3.

A well-known feature of standard RBC models is that they produce large correlations of consumption and investment growth. As shown in Table 5, Model 2 and Model 3 share this feature. This result is driven by the existence of only one source of uncertainty, the shortrun productivity shock. Since both consumption and investment co-move with this shock, the correlation of their growth rates is quite high. In the data, instead, the correlation of consumption and investment growth during the sample period 1929-2008 is 39\%, much lower value than that produced by Model 1 and Model 2. Both our Benchmark model and 
Model 1 are consistent with this feature of the data: the correlation between consumption and investment growth is $28 \%$ in the Benchmark model and $47 \%$ in Model 1. These results are driven by the introduction of long-run productivity uncertainty. Realizations of longrun productivity shocks, in fact, affect the return of new investments but have little effect on the total output in the current period. By resource constraint, therefore, consumption and total investment must move in opposite directions in response to these shocks, reducing their unconditional correlation.

\section{(INSERT TABLE 5 HERE)}

\section{Asset Price Dynamics}

In this section we examine the asset pricing implications of our model. We show that quantitatively, the lagged risk exposure of new vintage capital plays an essential rule in accounting for the high market equity premium and the high spread between tangible and intangible capital.

Campbell (2000) summarizes the challenge to general equilibrium asset pricing models as three puzzles: the equity premium puzzle (Mehra and Prescott (1985)), the stock market volatility puzzle (Campbell (1999)), and the risk-free rate puzzle (Weil (1989)). The above three puzzles manifest themselves even stronger in production economies. In fact, the production economy setting provides additional challenges: the economy must not only have a pricing kernel that is volatile enough, but also endogenously produce a high volatility of the stock market returns. We know several possible mechanisms that generate a highly volatile stochastic discount factor, for example, the habit persistence model of Campbell and Cochrane (1999), the long-run risk model of Bansal and Yaron (2004) and the rare disaster model of Reitz (1988) and Barro (2006). On the return volatility puzzle, the literature has

relied primarily on adjustment cost, or other forms of rigidity in investment to generate the variation in the price of physical capital. As we explain below, relying on rigidity in investment as the only channel to generate variations in the price of physical capital is problematic if the model is also asked to respect the empirical evidence on the low volatility of the risk-free interest rate, and the high variance of the aggregate tangible investment. Our calibration, however, shows that the heterogenous productivity of capital of different vintages is important in understanding the coexistence of the high volatility of the stock market return, the high volatility of aggregate investment, and the low volatility of the risk-free interest rate.

The empirical evidence on value premium puts a strong discipline on general equilibrium 
asset pricing models with intangible capital. It is a well-documented empirical fact that stocks with high book-to-market ratio earn higher returns over the long run. The difference in the average return of the highest book-to-market ratio portfolio and the lowest bookto-market ratio portfolio is about $5.92 \%$ per year for the period 1929-2003. This evidence suggests that intangible capital earns a lower average return than physical capital since book value measures the value of a firm's physical asset, and the difference between market value and book value can be attributed to the value of intangible capital owned by the firm. Qualitatively, the Benchmark model and Model 1 and 2 are consistent with intangible capital being less risky in equilibrium (Ai (2009b)). Quantitatively, however, only our Benchmark model is capable to produce a significant value premium. The key to understand the high value premium in the Benchmark model is the interaction between lagged risk exposure of new vintage capital and long-run productivity risk.

The rest of the subsections is organized as follows. We first discuss the common feature of all four calibrations in Section C.1. We examine the models' implications on the volatility of returns $r_{K}$ and $r_{S}$ in Section C.2. Finally, we study the models' implications of value premium in Section C.3. The asset pricing implications of all four calibrations are summarized in Table 5.

\section{C.1 Common Features}

In standard RBC models, there is always a tension in simultaneously producing a high consumption-physical investment ratio and a low level of the risk-free rate through the subjective discount factor $\beta$. This explains why in Model 3 we are not able to match the level of the risk-free rate, as we set $\beta$ to reproduce the consumption-investment ratio observed in the data.

Introducing intangible investment reduces the steady state share of physical investment

and mitigates this tension. In all the other models, we are able to generate a low and relatively smooth risk-free interest rate. The level of the risk-free interest rate is matched through a higher discount factor $\beta$. The volatility of the risk-free interest rate is low because we adopt an IES greater than one: since agents are very willing to substitute consumption across time, fluctuations in expected consumption growth rate only produce small variations in the equilibrium interest rate.

All four models produce a fairly high volatility of the stochastic discount factor. Since the representative agent is endowed with recursive preferences, fluctuations in expected consumption growth (long-run risk in the language of Bansal and Yaron (2004)) strongly affect marginal utility. Model 2 and 3 feature predictability in consumption growth because 
of the endogenous fluctuations in $K$ and $S$. Introducing intangible capital almost doubles the volatility of the stochastic discount factor. As explained earlier, both in the Benchmark model and Model 1, long-run productivity uncertainty produces substantial variations in the predictable component of consumption growth, in turn increasing further the market price of risk.

\section{C.2 Volatility of Returns}

As shown in Lochstoer and Kaltenbrunner (2008) and Croce (2008), an important challenge to long-run risk based asset pricing model with production is to account for the high volatility of investment and stock returns simultaneously. Although recursive preferences generate high volatility of the stochastic discount factor, the return to physical capital is typically very smooth, unless one is willing to assume a large adjustment cost. High levels of adjustment cost, however, are typically associated with counterfactually low levels of volatility in investment growth.

This tension is present in Model 1, 2, and 3, but it is resolved in our Benchmark model where the annual volatility of the returns on physical capital is $2.15 \%$, and investment is as volatile as in a RBC model. In order to explain our results, we find it convenient to plot in Figure 1 and 2 the impulse response functions of, respectively, quantities and prices with respect to both short-run (left panels) and long-run shocks (right panels). In both figures, solid lines refer to Model 1, while dashed lines are generated from the Benchmark model. Note that the impulse response functions with respect to short-run productivity shocks are remarkably similar to each other, but they are significantly different when we focus on long-run shocks.

Although the response of the stochastic discount factor to a long-run productivity shock is almost identical in both models, those of the returns on physical capital are dramatically different (Figure 2, third panel on the right column). With a one standard deviation change in the long-run productivity shock, the return on physical capital, $r_{K}$, in the Benchmark model increases by about $1.5 \%$, while the change of that in Model 1 is barely visible. This implies that the exposure to long-run productivity risk of physical capital is very small in Model 1, while that in the Benchmark model is larger by several orders of magnitude.

In order to explain the different behavior of $r_{K}$ across the Benchmark model and Model 1 , we need to focus our attention on the price of physical capital, $q_{K}$ (Figure 2, fourth panel on the right column). Equation (18) implies that the price of physical capital, $q_{K}$ is the present value of the marginal product of physical capital in all future periods (This equation holds in Model 1 as well). A positive innovation in the long-run productivity component $x_{t}$ 
has two effects on the future marginal product of physical capital. The first one is a direct effect: keeping everything else constant, an increase in $x_{t}$ raises the marginal product of physical by increasing all future $A_{t+j}$ for $j=1,2 \cdots$. The second effect comes from the general equilibrium: an increase in the marginal productivity of capital also triggers more investment, which augments $K_{t+j}$ in all future periods. Due to decreasing return to scale $(\alpha<1)$, an increase in $K_{t+j}$ mitigates the direct effect.

In Model 1, the elasticity of substitution between physical investment and intangible capital, $\eta$, is set to 1.4. This implies that the supply of new capital is quite flexible, explaining why the return on physical capital almost does not adjust after long-run shocks. To better see this point, note that without overlapping generations of vintage capital, we have $\varpi_{t}=1 \quad \forall t$, and Equation (13) can be written as:

$$
q_{K}(z)-\left(1-\delta_{S}\right)=\frac{1}{G_{I}(I, S)}=\frac{1}{\nu}\left(\frac{I}{G(I, S)}\right)^{\frac{1}{\eta}} .
$$

By Equation (24), as $\eta$ increases, $I$ becomes more sensitive to changes in $q_{K}$. Equation (18) implies that if investment adjusts elastically to productivity shocks, then the effect of long-run productivity shock on $q_{K}$ is small due to decreasing return to scale of physical capital. This intuition is confirmed by our impulse response functions. In Figure 1, we see that innovations in long-run productivity shock are accompanied by a nearly permanent increase in the $I / S$ ratio (third panel, right column, blue line). As a result, the changes in $q_{K}$ after a long-run productivity shock is almost negligible (Figure 2, 4th panel of the right column). Summarizing, in Model 1 the return of physical capital responds little to long-run productivity shocks because the direct effect on the price of physical capital is mostly offset by movements in investment (general equilibrium effect). Like with standard adjustment costs, Model 1 finds it difficult to simultaneously produce a high volatility of investment growth and returns on physical capital.

In the Benchmark model, instead, after a long-run productivity shock, investment rises only with a long delay, while the return on physical capital increases immediately and sharply. Figure 1 shows that the $I / S$ ratio initially drops and then starts to rise, always staying below the level obtained in Model 1 (fourth panel, right column). The last panel in the same column plots the impulse response of physical capital stock normalized by productivity $\left(k_{t}=K_{t} / A_{t}\right)$ after a long-run shock. Because of the lagged response of investment, the level of physical capital in the Benchmark model stays nearly permanently behind that obtained in Model 1. These dynamics have a precise implication for the marginal product 
of physical capital, which is a decreasing function of normalized capital stock, $k$ :

$$
\frac{\partial}{\partial K}\left[A^{1-\alpha} K^{\alpha}\right]=\alpha\left(\frac{A}{K}\right)^{1-\alpha}=\frac{\alpha}{k^{1-\alpha}} .
$$

In the Benchmark model, therefore, the marginal product of physical capital stays almost permanently above that observed in Model 1, producing a strong increase in $q_{K}$. In this case, both the direct and the general equilibrium effect of long-run productivity shocks affect $q_{K}$ in the same way, reinforcing each other. Basically, the marginal product of capital increases both because a positive shock in $x_{t}$ increases $A_{t+j}$ in all future periods, and because the sluggish response of investment to long-run shocks results in a nearly permanent reduction of physical capital stock relative to that in Model 1.

To understand the negative response of investment to long-run news in the Benchmark model, note that a long-run shock increases the productivity of all existing vintages of capital permanently, but affects the productivity of the new production units only with a delay. This generates an incentive to post-pone the exercise of new investment options. As a result, a long-run productivity shock immediately produces a strong income effect (the agent anticipates a persistent increase in the productivity of all existing vintages of capital and prefers to consume more) without generating a significant substitution effect, i.e. there is no incentive to generate immediately new investment. At time 1, when a positive long-run shock materializes, the net effect is an immediate increase in consumption and a decrease in investment, exactly the opposite of what happens in Model 1, where the substitution effect dominates the income effect and investment increases.

In the Benchmark model, it may be surprising to see that positive long-run shocks, although small, have quite significant and prolonged negative effects on physical investment. The sluggish response of investment is generated by the persistence of the long-run shocks: after positive long-run news, the relative productivity of new investment remains behind that of existing vintages for an extended period of time, therefore discouraging a fast and full recovery of investment.

Our model explains the link between productivity shocks and stock market fluctuations, but does not feature dividend-specific shocks. In the data, however, it is well known that dividend-specific shocks explain a substantial share of the volatility of the market returns. Consequently, our model cannot and should not account for the total volatility of the stock market returns. In the rest of this section we evaluate how much productivity-related stock market fluctuations our model can account for.

First of all, under the guidance of our model, we construct a measure of productivity- 
related return volatility by projecting returns onto the space of long-run and short-run productivity shocks. For any return $r_{t}$, we denote

$$
\hat{r}_{t}=E\left[r_{t} \mid \Delta x_{t}, \Delta \ln A_{t}\right]
$$

as the return projected onto the space of productivity shocks. Second, we define the productivity-related volatility of the return $r_{t}$ as follows.

Definition 1 Productivity-related Volatility

The productivity-related volatility of a return $r_{t}$, denoted as $\hat{\sigma}$, is defined as the volatility of the return projected onto the space of productivity shocks, that is,

$$
\hat{\sigma}=\operatorname{Std}\left[\hat{r}_{t}\right]
$$

where $\hat{r}_{t}$ is the projection of return $r_{t}$ onto the space of productivity shocks defined in (25).

In practice, we calculate the conditional expectation in (25) by the following regression: ${ }^{10}$

$$
r_{M, t}=\xi_{0}+\xi_{1} \Delta x_{t}+\xi_{2} \Delta \ln A_{t}+\varepsilon_{t} .
$$

A potential difficulty of calculating $\hat{r}_{t}$ is that $\Delta x_{t}$ is unobservable in the data and needs to be substituted by an estimated proxy, $\Delta \hat{x}_{t}$. A merit of our approach is that we do not need to measure the latent variable $\Delta x_{t}$ accurately in order to accurately compute $\hat{\sigma}$. Since we are only interested in the conditional expectation, as long as the couple $\left(\Delta \hat{x}_{t}, \Delta \ln A_{t}\right)$ spans the whole space of productivity shocks, we can obtain a perfect measure of $\hat{\sigma}$. The details of the construction of $\hat{\sigma}$ in the data and the model can be found in the Appendix $\mathrm{C}$ of the paper. ${ }^{11}$

According to our procedure, only $25 \%$ of the total observed volatility of the market returns can be attributed to productivity shocks. Therefore, while in our sample the total volatility of the returns is $19.42 \%$, the volatility directly related to productivity is in the order of $5.25 \%$. After leveraging our returns, our model accounts for almost all productivityrelated volatility of the stock market, as shown in the last row of Table $5{ }^{12}$

\footnotetext{
${ }^{10}$ Here we are assuming that the conditional expectation is linear in the short-run and long-run shocks. It turns out this is a very good approximation under the null of the model.

${ }^{11}$ Our empirical investigation confirms that our calculation of productivity-related volatility of the market returns is robust to various methods of estimation both in the data and in the model simulations.

${ }^{12} \mathrm{We}$ assume a leverage ratio (the ratio of debt-to-equity) of 2.
} 
We conclude this section by pointing out that the volatility puzzle is more severe in economies with decreasing marginal returns of physical capital (see also Lochstoer and Kaltenbrunner (2008) and Croce (2008)). In AK models, such as the one studied in Ai (2009a), the response of investment to productivity shocks does not dampen the direct effect of productivity shocks on returns, hence generating a volatile return on capital is easier. While AK models are useful in studying economic growth in the long-run, empirical studies (see, for example, Benhabib and Jovanovic (1991), Benhabib and Spiegel (1994), Romer (1990), King and Levine (1994)) emphasize the importance of decreasing returns to physical capital in understanding macroeconomic quantities. Given this empirical evidence, our work suggests that different exposure of capital vintages to productivity risk is important to explain productivity-related volatility of market returns.

\section{C.3 Value Premium}

To understand the difference in the expected return of tangible and intangible capital, we can use the functional form of $G(I, S)$ in Equation (23) and write the return of intangible capital in Equation (17) as:

$$
r_{S}\left(z, z^{\prime}\right)=\frac{1-\nu}{\nu}\left(\frac{I\left(z^{\prime}\right)}{S^{\prime}}\right)^{\frac{1}{\eta}}+\left(1-\delta_{S}\right) .
$$

The term $\frac{1-\nu}{\nu}\left(\frac{I\left(z^{\prime}\right)}{S^{\prime}}\right)^{\frac{1}{\eta}}$ can be interpreted as the current-period option value of intangible capital. After noticing that $S$ is pre-determined, it is easy to see that this term is increasing in $I$, as more physical investment allows more investment options to be exercised, and therefore increases the "moneyness" of the options. Equation (27) implies that the riskiness of intangible capital depends on the sensitivity of the $I / S$ ratio to productivity shocks.

The implications of our model on the value premium are summarized in the last panel of Table 5. We make the following observations. First, all models with intangible capital yield a higher return for physical capital than for intangible capital. This result can be explained by noticing that intangible is risky only because the "dividend" component of the return in (27), that is $\frac{1-\nu}{\nu}\left(\frac{I\left(z^{\prime}\right)}{S^{\prime}}\right)^{\frac{1}{\eta}}$ is risky, while $q_{S, t}=1 \quad \forall t$.

Second, comparing Model 1 and Model 2, we can see that adding long-run productivity shock raises the market risk premium only slightly, but eliminates most of the spread between tangible and intangible capital produced by Model 1. On the one hand, without overlapping generations of vintage capital, the response of $q_{K}$ to long-run productivity shock is very small. On the other hand, because the $I / S$ ratio increases quite strongly in response 
to a long-run productivity shock (see the third panel in the right column of Figure 1), and because long-run productivity shock requires a large risk premium (see the second panel in the right column of Figure 2), intangible capital is significantly more risky in Model 1 than in Model 2.

Finally, compared to Model 1, our Benchmark model produces both a larger risk premium on physical capital and a smaller risk premium on intangible capital, thus improving upon Model 1 on both dimensions of equity and value premium. Overlapping generations of vintage capital dampen the response of physical investment to long-run productivity shocks and increase the risk exposure of physical capital. At the same time, the $I / S$ ratio responds negatively to long-run productivity shocks in the first period, making intangible capital a good insurance device against the long-run risk. This is evident in Figure 2 (last panel, right-column): the return of intangible capital responds negatively to long-run productivity shocks. Overall, the Benchmark model produces a market risk premium more than two times larger than that in Model 1, and a spread between tangible and intangible capital higher by an order of magnitude. When leverage is taken into account, the benchmark model produces a value premium of $4.29 \%$ per year, more than $70 \%$ of the observed value premium in the data.

\section{Conclusion}

We present a general equilibrium asset pricing model with intangible capital to account for some of the salient features of macroeconomic quantity and asset price dynamics. Incorporating intangible presents additional challenges to general equilibrium asset pricing models with production. Due to the well known difficulty in generating a high equity premium in production economies, one might be tempted to assume that intangible capital is much more risky than physical capital and propose this as a resolution of the equity premium puzzle. The empirical evidence on value premium, however, suggests the exact opposite. In the US, portfolios of firms with low book-to-market ratios pay substantially lower returns than firms with high book-to-market. This suggests intangible capital earns a much lower risk premium than tangible capital, making it even harder to account for the overall market equity premium.

We document a novel empirical evidence that is the key to understand the empirical facts on equity returns, especially the spread between tangible and intangible capital. We show that in the data new investment is less exposed to aggregate productivity shocks than capital of older vintages. We build a general equilibrium model with intangible capital 
based on Ai (2009b) and incorporate long-run productivity risk as in Croce (2008). We show that the lower exposure of new investment is quantitatively important in accounting for the high equity premium, the high volatility of the stock market return, and the high spread between book-to-market sorted portfolios in the data.

Several remarks are in order. First, our model is silent on why young firms are much less exposed to aggregate risk than older firms, but this seems to be an important and interesting future research question. Second, there are many other important issues that could be studied in our framework. For example, the dynamics of hours worked, the predictability of stock market returns, the term structure of interest rates. Based on the insights from Bansal and Yaron (2004), and Bansal, Kiku, and Yaron (2007), we conjecture that building a timevarying volatility in aggregate productivity is a promising direction. Finally, we believe that our model provides a general equilibrium framework to measure intangible capital by exploring the information from both the quantity and pricing side of the economy. 
Table 1: Summary Statistics by Firm's Age

\begin{tabular}{lccccc}
\hline \hline Age Groups (yrs) & Avg. Age & Avg. Y & Avg. K & Avg. N & No. of Obs. \\
\hline $1-10$ & 4.91 & 1.00 & 1.00 & 1.00 & $61.60 \%$ \\
$11-20$ & 14.72 & 2.48 & 2.92 & 2.59 & $22.69 \%$ \\
$21-30$ & 24.94 & 5.70 & 8.25 & 5.81 & $9.30 \%$ \\
$31-40$ & 34.87 & 13.20 & 26.05 & 11.94 & $4.27 \%$ \\
41 and above & 46.75 & 33.78 & 104.58 & 23.57 & $2.15 \%$ \\
Total & & & & & \\
\hline \hline
\end{tabular}

This table reports the summary statistics of the firms in our sample for five age groups, 1-10, 11-20, 21-30, 31-40 and 41 years and above. The abbreviation Avg. Y stands for the average output, Avg. $\mathrm{K}$ for average capital stock, and Avg. $\mathrm{N}$ for average number of employees. We normalize average output, average capital stock, and average number of employees of the age group 1-10 to 1 . In the last column we report the percentage number of observations in our sample for each age group. 
Table 2: Exposure to Aggregate Risk by Firms' Age

\begin{tabular}{|c|c|c|c|c|}
\hline & \multicolumn{2}{|c|}{ Without Fixed Effect } & \multicolumn{2}{|c|}{ With Fixed Effect } \\
\hline & First Stage & Second Stage & First Stage & Second Stage \\
\hline \multirow[t]{2}{*}{ Capital Share $\left(\alpha_{1}\right)$} & $0.390^{* * *}$ & & $0.359^{* * *}$ & \\
\hline & $(0.001)$ & & $(0.005)$ & \\
\hline \multirow[t]{2}{*}{ Labor Share $\left(\alpha_{2}\right)$} & $0.534^{* * *}$ & & $0.519^{* * *}$ & \\
\hline & $(0.002)$ & & $(0.008)$ & \\
\hline \multirow[t]{2}{*}{ Age Effect $\left(\xi_{3}\right)$} & & $0.031^{* * *}$ & & $0.031^{* * *}$ \\
\hline & & $(0.006)$ & & $(0.006)$ \\
\hline$R^{2}$ & 0.859 & 0.036 & 0.618 & 0.037 \\
\hline No. of Firms & 19,639 & 18,017 & 19,639 & 18,017 \\
\hline No. of Observations & 220,570 & 195,343 & 220,570 & 195,343 \\
\hline
\end{tabular}

This table reports firms' risk exposure by age. The column "First Stage" reports the statistics of the first stage regression. The column "Second Stage" reports the statistics of the second stage regression. The statistics for the regression "With Fixed Effect" is based on regression (22). The regression "Without Fixed Effect" is based on the same regression without the fixed effect term $\xi_{0, i}$. We use $* * *$ to indicate a p-value of less than 0.001 . 
Table 3: Calibrated Parameter Values

\begin{tabular}{lccccc}
\hline \hline MODEL: & & Benchmark & 1 & 2 & 3 \\
\hline Preference Parameters & & & & & \\
\hline Discount Factor & $\beta$ & 0.97 & 0.97 & 0.98 & 0.89 \\
Risk Aversion & $\gamma$ & 10 & 10 & 10 & 10 \\
Intertemporal Elasticity of Substitution & $\psi$ & 2.0 & 2.0 & 2.0 & 2.0 \\
& & & & & \\
Production Function/Aggregator Parameters & & & & & \\
\hline Capital Share & $\alpha$ & 0.3 & 0.3 & 0.3 & 0.3 \\
Depreciation Rate of Physical Capital & $\delta_{K}$ & $10 \%$ & $10 \%$ & $10 \%$ & $10 \%$ \\
Depreciation Rate of Intangible Capital & $\delta_{S}$ & $10 \%$ & $10 \%$ & $10 \%$ & - \\
Weight on Physical Investment & $\nu$ & 0.84 & 0.79 & 0.815 & - \\
Elasticity of Substitution & $\eta$ & 1.40 & 1.40 & 1.75 & - \\
& & & & & \\
TFP Parameters & & & & & \\
\hline Average Growth Rate & $\mu$ & $2.0 \%$ & $2.0 \%$ & $2.0 \%$ & $2.0 \%$ \\
Volatility of Short-run Risk & $\sigma_{a}$ & $5.00 \%$ & $6.30 \%$ & $7.00 \%$ & $5.00 \%$ \\
Volatility of Long-run Risk & $\sigma_{x}$ & $0.85 \%$ & $0.85 \%$ & - & - \\
Autocorrelation of Expected Growth & $\rho$ & 0.93 & 0.93 & - & - \\
New investment's risk exposure & $\phi$ & 0 & 1 & 1 & 1 \\
\hline \hline
\end{tabular}

This table reports the parameter values used for our calibrations. The risk aversion, $\gamma$, intertemporal elasticity of substitution, $\psi$, capital share, $\alpha$, depreciation rates, $\delta_{K}$ and $\delta_{S}$, and the average productivity growth rate, $\mu$, are common across all models. We choose the rest of the parameters to match the moments reported in table 4 whenever possible. All models are calibrated at an annual frequency. 
Table 4: Moments used for Model Calibration

\begin{tabular}{lccccc}
\hline \hline & DATA & BENCHMARK & MODEL 1 & MODEL 2 & MODEL 3 \\
\hline$E[C / I]$ & 5.62 & 5.60 & 5.62 & 5.62 & 5.64 \\
$E[I / J]$ & 1.00 & 1.01 & 0.98 & $(0.80)$ & - \\
$\sigma[\Delta \ln Y]$ & 3.49 & 3.49 & 3.49 & 3.49 & 3.50 \\
$A C 1[\Delta \ln Y]$ & 0.45 & 0.45 & $(0.49)$ & $(0.30)$ & $(0.27)$ \\
$E\left[r_{f}\right]$ & 0.86 & 0.86 & 0.87 & 0.86 & $(12.65)$ \\
\hline \hline
\end{tabular}

This table reports the moments used to calibrate the parameters of the models evaluated in this paper. All moments that cannot be matched are into parentheses. In Model 3, the discount factor $\beta$ is chosen to match the steady-state consumption-investment ratio, even though this makes the riskfree interest rate too high. Both Model 2 and 3 cannot match the persistence of output growth, since they have no long-run risk. In Model 2, the parameter $\nu$ is set to match the consumption-investment ratio even though the implied $I / J$ ratio is lower than in the data. In Model 1, the autocorrelation of output cannot be matched, as we decide to keep the calibration of the long-run risk component constant across models. 
Table 5: Quantities and Prices

\begin{tabular}{lccccc}
\hline \hline MOMENTS & DATA & BENCHMARK & MODEL 1 & MODEL 2 & MODEL 3 \\
\hline$\sigma(\Delta \ln C)$ & 02.93 & 02.87 & 02.95 & 02.83 & 02.47 \\
$\sigma(\Delta \ln I)$ & 16.40 & 12.48 & 09.20 & 08.87 & 12.61 \\
$C \operatorname{cor} r(\Delta \ln C, \Delta \ln I)$ & 00.39 & 00.26 & 00.62 & 00.76 & 00.82 \\
$A C_{1}(\Delta \ln C)$ & 00.49 & 00.54 & 00.55 & 00.51 & 00.34 \\
\hline$\sigma[S D F]$ & - & 93.09 & 98.21 & 68.08 & 39.01 \\
$E\left[r_{K}-r_{f}\right]$ & - & 02.00 & 00.80 & 00.72 & 00.28 \\
$\sigma\left[r_{K}\right]$ & - & 02.15 & 01.46 & 01.37 & 00.98 \\
$E\left[r_{S}-r_{f}\right]$ & - & 00.55 & 00.65 & 00.44 & - \\
$\sigma\left[r_{S}\right]$ & - & 01.19 & 01.12 & 00.89 & - \\
\hline$E\left[r_{f}\right]$ & 00.86 & 00.86 & 00.86 & 00.86 & 12.65 \\
$\sigma\left[r_{f}\right]$ & 00.97 & 01.18 & 01.10 & 00.75 & 00.68 \\
$E\left[r_{M}^{L}-r f\right]$ & 05.48 & 04.74 & 02.22 & 02.16 & 00.85 \\
$\widehat{\sigma}_{M}$ & 05.24 & 04.98 & 02.98 & 03.14 & 02.27 \\
$E\left[r_{K}^{L}-r_{S}^{L}\right]$ & 05.00 & 04.08 & 00.44 & 01.11 & - \\
\hline \hline
\end{tabular}

All figures are multiplied by 100, except correlations. Empirical moments are computed using US annual data from 1930 to 2003 . The entries for the models are obtained by simulations. $r_{M}^{L}$ indicates levered market returns; $\hat{\sigma}_{M}$ measures the volatility of market returns explained by productivity. $E\left[r_{K}^{L}-r_{S}^{L}\right]$ measures the average difference between the levered returns of tangible and intangible capital. We use a leverage coefficient of 3. $A C_{1}$ indicates first order auto-correlation. All the parameters are calibrated as in table 3 . 

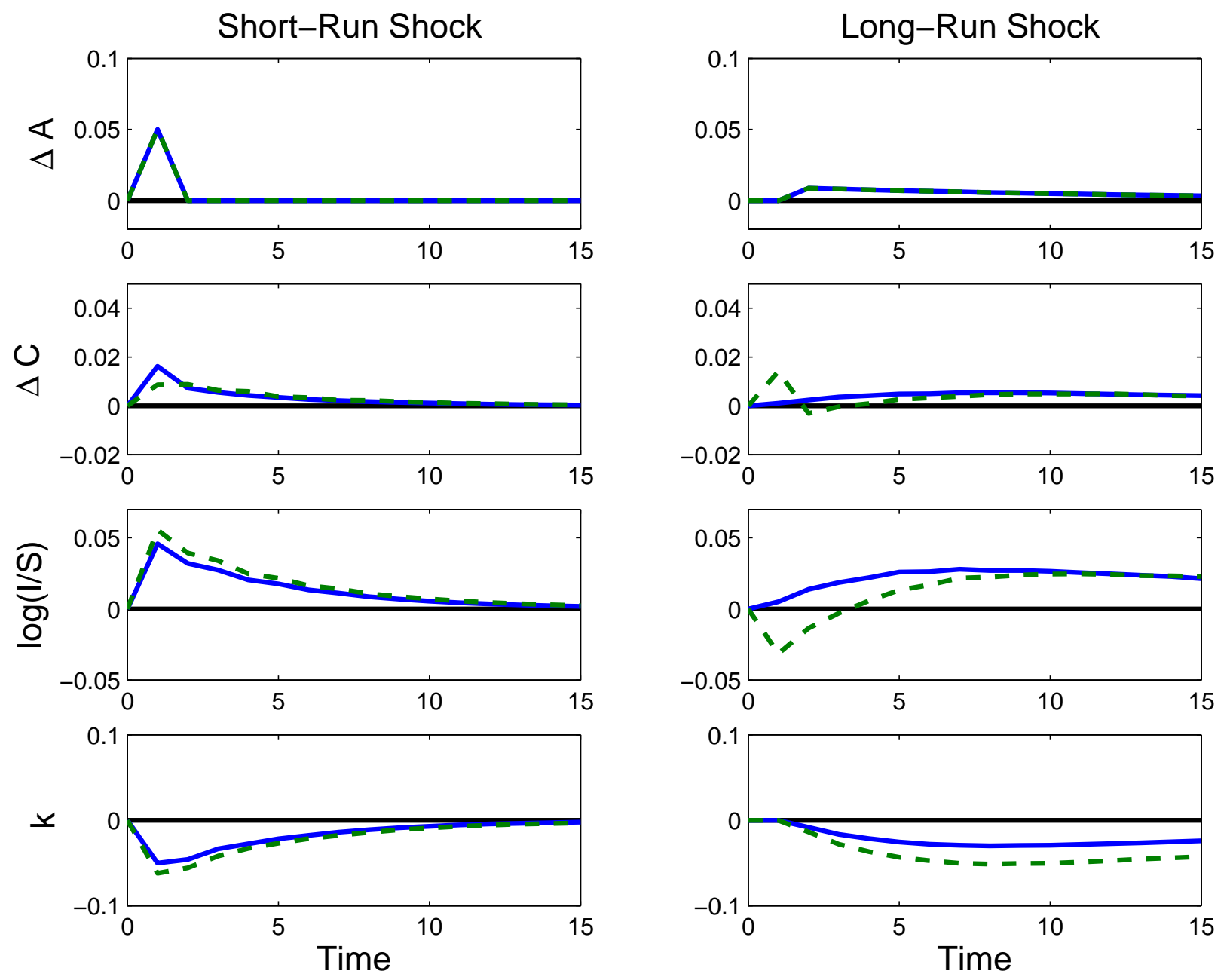

Fig. 1 - Impulse Response Functions for Quantities

This figure shows annual log-deviations from the steady state. All the parameters are calibrated to the values reported in Table 3. The solid lines refer to Model 1, while the dashed lines refer to the Benchmark model. 

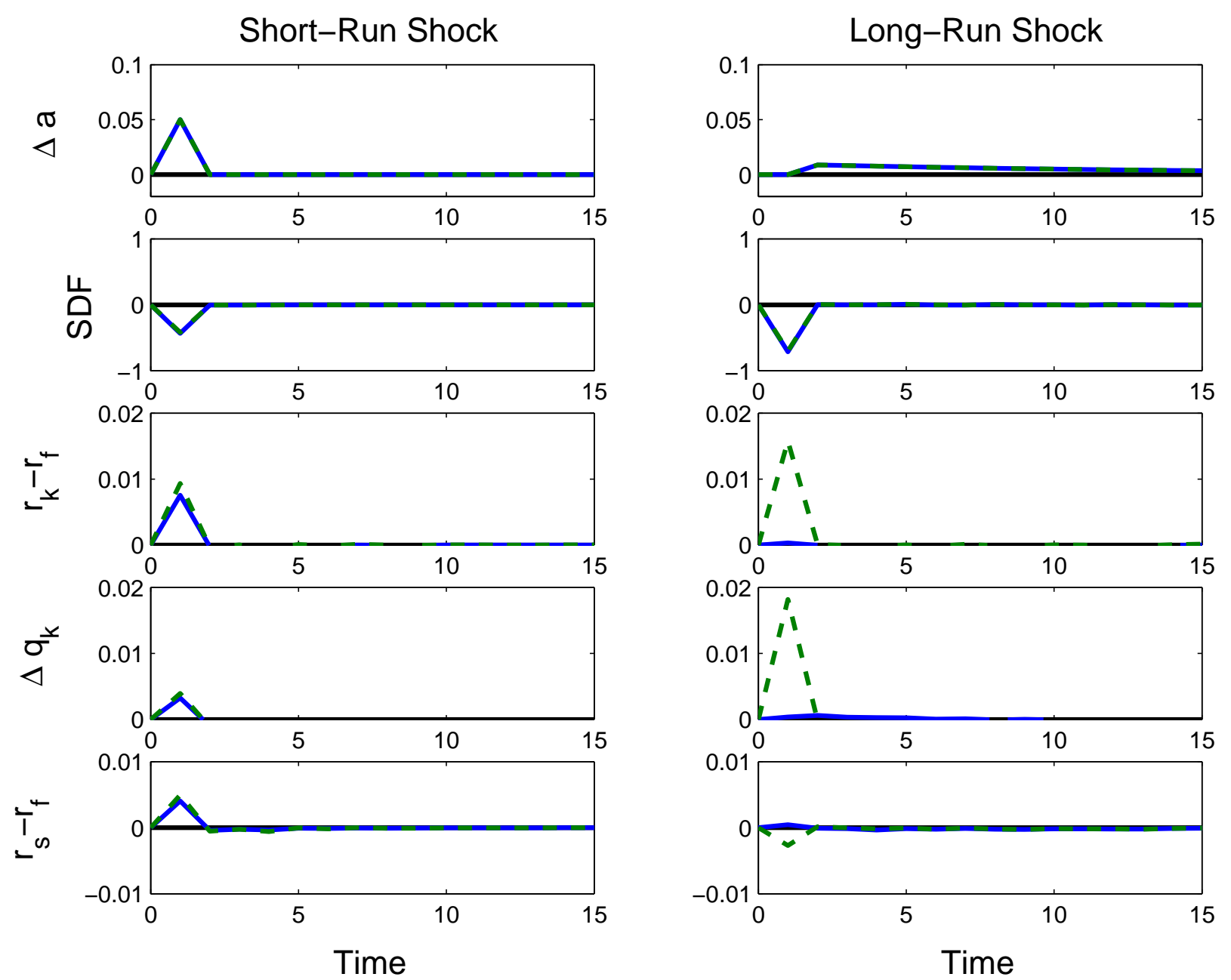

Fig. 2 - Impulse Response Functions for Prices

This figure shows annual log-deviations from the steady state. All the parameters are calibrated to the values reported in Table 3. Returns are not levered. The solid lines refer to Model 1, while the dashed lines refer to the Benchmark model. 


\section{References}

Ai, H. (2009a). Information quality and long-run risk: Asset pricing implications. Journal of Finance (forthcoming).

Ai, H. (2009b). Intangible capital and the value premium.

Ai, H. and D. Kiku (2009, August). Growth to value: Option exercise and the cross-section of equity returns.

Bansal, R., R. Dittmar, and C. Lundblad (2005, August). Consumption, dividends, and the cross section of equity returns. The Journal of Finance 60(4), 1639-1672.

Bansal, R., D. Kiku, and A. Yaron (2007, September). Risks for the long run: Estimation and inference.

Bansal, R. and A. Yaron (2004, August). Risk for the long run: A potential resolution of asset pricing puzzles. The Journal of Finance 59(4), 1481-1509.

Barro, R. (2006, August). Rare disasters and asset markets in the twentieth century. Quarterly Journal of Economics 121(3), 823-866.

Benhabib, J. and B. Jovanovic (1991, March). Externalities and growth accounting. The American Economic Review 81(1), 82-113.

Benhabib, J. and M. M. Spiegel (1994). The role of human capital in economic development evidence from aggregate cross-country data. Journal of Monetary Economics 34(2), 147-173.

Berk, J., R. C. Green, and V. Naik (1999). Optimal investment, growth options, and security returns. The Journal of Finance 54, 1553-1608.

Boldrin, M., L. Christiano, and J. Fisher (2001, March). Habit persistence, asset returns, and the business cycle. American Economic Review 91(1), 149-166.

Brock, W. and L. Mirman (1972, June). Optimal economic growth and uncertainty: The discounted case. Journal of Economic Theory 4 (3), 479-513.

Campanale, C., R. Castro, and G. Clementi (2008). Asset pricing in a production economy with chew-dekel preferences. Forthcoming on the Review of Economic Dynamics.

Campbell, J. (1999). Asset Prices, Consumption, and the Business Cycle, Volume 1 of Handbook of Macroeconomics. North-Holland: Amsterdam.

Campbell, J. (2000, August). Asset pricing at the millennium. Journal of Finance 55, 1515-1567.

Campbell, J. and J. Cochrane (1999, April). By force of habit: A consumption-based explanation of aggregate stock market behavior. Journal of Political Economy 107, 205-251. 
Carlson, M., A. Fisher, and R. Giammarino (2004, December). Corporate investment and asset price dynamics: Implications for the cross-section of returns. The Journal of Finance 59(6), $2577-2603$.

Cooper, I. (2006, February). Asset pricing implications of nonconvex adjustment costs and irreversibility of investment. The Journal of Finance 61(1), 139-170.

Corrado, C., C. Hulten, and D. Sichel (2005). Measuring Capital and Technology: An Expanded Framework, Volume 65 of Studies in Income and Wealth. Chicago: The University of Chicago Press.

Corrado, C., C. Hulten, and D. Sichel (2006). Intangible capital and economic growth.

Croce, M. M. (2008). Long-run productivity risk: A new hope for production-based asset pricing.

Dhawan, R. (2001, March). Firm size and productivity differential: Theory and evidence from a panel of us firms. 44(3), 269-293.

Epstein, L. and S. E. Zin (1989, July). Substitution, risk aversion, and the temporal behavior of consumption and asset returns: A theoretical framework. Econometrica 57(4), 937-969.

Gomes, J., L. Kogan, and L. Zhang (2003, August). Euqilibrium cross section of returns. Journal of Political Economy 111(4).

Gourio, F. (2009, September). Disaster risk and business cycles.

Hansen, G. (1985, November). Indivisible labor and the business cycle. Journal of Monetary Economics 16(3), 309-327.

Heckman, J. (1979). Sample selection bias as a specification error. Econometrica 47(1), 153-162.

Jermann, U. J. (1998, April). Asset pricing in production economies. Journal of Monetary Economics 41(2), 257-275.

Jovanovic, B. (2008, May). Investment options and the business cycle. Journal of Economic Theory.

Kiku, D. (2006). Long run risks and the value premium puzzle. Working paper, Duke University.

King, R. G. and R. Levine (1994). Capital fundamentalism, economic development, and economic growth. Carnegie Rochester Conference Series on Public Policy 40, 259-292.

Kydland, F. and E. Prescott (1982, November). Time to build and aggregtae fluctuations. 50(6), $1345-1370$.

Lochstoer, L. and G. Kaltenbrunner (2008, July). Long-run risk through consumption smoothing.

McGrattan, E. R. and E. C. Prescott (2005, July). Taxes, regulations, and the value of u.s. and u.k. corporations. Review of Economic Studies 72(3), 767-796.

McGrattan, E. R. and E. C. Prescott (2009a). Technology capital and the u.s. current account. American Economic Review, forthcoming. 
McGrattan, E. R. and E. C. Prescott (2009b). Unmeasured investment and the puzzling u.s. boom in the 1990s. American Economic Journal: Macroeconomics, forthcoming.

Mehra, R. and E. Prescott (1985, March). The equity premium: A puzzle. Journal of Monetary Economics 15(2), 145-161.

Panageas, S. and J. Yu (2006). Technological growth, asset pricing, and consumption risk over long horizons.

Reitz, T. (1988, July). The equity risk premium: A solution. Journal of Monetary Economics 22(1), $117-131$.

Romer, P. (1990). Capital labor and productivity. Brookings Paper on Economic Activity, Microeconomic Special Issue, 337-367.

Rouwenhorst, K. G. (1995). Asset pricing implications of equilibrium business cycle models. In T. F. Cooley (Ed.), Frontiers of Business Cycle Research, Chapter 10, pp. 294-330. Princeton, NJ: Princeton University Press.

Tallarini, T. D. (2000, June). Risk sensitive real business cycles'. Journal of Monetary Economics $45(3), 507-532$.

Weil, P. (1989, January). The equity premium puzzle and the riskfree rate puzzle. Journal of Monetary Economics $24(3), 401-422$.

Zhang, L. (2005, February). The value premium. The Journal of Finance 60(1), 67-103. 


\section{Appendix}

\section{Appendix A: Aggregation of Production Units}

Lemma 1 Suppose there are $m$ types of firms. For $i=1,2,3, \cdots m$, the productivity of the type $i$ firm is denoted by $A(i)$, and the total measure of type $i$ firm is denoted by $K(i)$. The production technology of type $i$ firm is given by

$$
y(i)=[A(i) n(i)]^{1-\alpha}
$$

where $n(i)$ denotes the labor hired at firm $i$. The total labor supply in the economy is $N$. Then the aggregate production function is given by:

$$
Y=\left[\sum_{i=1}^{m} K(i)\left[\frac{A(i)}{A(1)}\right]^{\frac{1-\alpha}{\alpha}}\right]^{\alpha}[A(1) N]^{1-\alpha}
$$

Proof. Without loss of generality, we assume at the optimal production plan, firms of the same type employ the same amount of labor. The total production in the economy is given by:

$$
\begin{gathered}
Y=\max \sum_{i=1}^{m} K(i) A(i)^{1-\alpha} n(i)^{1-\alpha} \\
\text { subject to } \sum_{i=1}^{m} K(i) n(i)=N
\end{gathered}
$$

The first order condition of the above optimization problem implies that for all $i$

$$
\frac{n(i)}{n(1)}=\left(\frac{A(i)}{A(1)}\right)^{\frac{1-\alpha}{\alpha}}
$$

Using the resouce constraint, we determine the labor employed in firm 1:

$$
\sum_{i=1}^{m} K(i)\left(\frac{A(i)}{A(1)}\right)^{\frac{1-\alpha}{\alpha}} n(1)=N
$$

This implies

$$
n(1)=\left[\sum_{i=1}^{m} K(i)\left[\frac{A(i)}{A(1)}\right]^{\frac{1-\alpha}{\alpha}}\right]^{-1} N
$$


Therefore the total production is given by

$$
\begin{aligned}
Y & =\sum_{i=1}^{m} K(i) A(i)^{1-\alpha}\left[\left(\frac{A(i)}{A(1)}\right)^{\frac{1-\alpha}{\alpha}} n(1)\right]^{1-\alpha} \\
& =\left[A(1)^{-\frac{1-\alpha}{\alpha}} n(1)\right]^{1-\alpha} \sum_{i=1}^{m} K(i) A(i)^{\frac{1-\alpha}{\alpha}} \\
& =\left[\sum_{i=1}^{m} K(i) A(i)^{\frac{1-\alpha}{\alpha}}\right]^{\alpha} N^{1-\alpha} \\
& =A(1)\left[\sum_{i=1}^{m} K(i)\left(\frac{A(i)}{A(1)}\right)^{\frac{1}{\alpha}}\right]^{\alpha} N^{1-\alpha}
\end{aligned}
$$

Plug in the expression for $n$ (1) in Equation (A.2), we have:

$$
\begin{aligned}
Y & =\left[A(1)^{-\frac{1-\alpha}{\alpha}}\left[\sum_{i=1}^{m} K(i)\left[\frac{A(i)}{A(1)}\right]^{\frac{1-\alpha}{\alpha}}\right]^{-1} N\right]^{1-\alpha} \sum_{i=1}^{m} K(i) A(i)^{\frac{1-\alpha}{\alpha}} \\
& =\left[\sum_{i=1}^{m} K(i) A(i)^{\frac{1-\alpha}{\alpha}}\right]^{\alpha} N^{1-\alpha} \\
& =\left[\sum_{i=1}^{m} K(i)\left[\frac{A(i)}{A(1)}\right]^{\frac{1-\alpha}{\alpha}}\right]^{\alpha} A(1)^{1-\alpha} N^{1-\alpha}
\end{aligned}
$$

as needed.

\section{Proof of Proposition 1:}

At time $t$, there are $t+1$ types of operating production units in the economy, namely, production units of generation $-1,0,1, \cdots, t-1$. The measure of these production units are $\left(1-\delta_{K}\right)^{t} K_{0}$, $\left(1-\delta_{K}\right)^{t-1} E_{0},\left(1-\delta_{K}\right)^{t-2} E_{1}, \cdots, E_{t-1}$. Using the above lemma, at date $t$, the total production in the economy is given by

$$
Y_{t}=A_{t}\left[\left(1-\delta_{K}\right)^{t} K_{0}+\sum_{j=0}^{t-1}\left(1-\delta_{K}\right)^{t-j-1} E_{j}\left(\frac{A_{t}^{j}}{A_{t}}\right)^{\frac{1-1}{\alpha}}\right]^{\alpha} N_{t}^{1-\alpha} .
$$

Clearly, if we define the $\left\{K_{t}\right\}_{t=0}^{\infty}$ according to (6), the aggregate production function can be summarized as in (5).

\section{Appendix B: Robustness Analysis of Firms' Risk Exposure}

We present robustness analysis for the empirical results reported in Section III. We first address the issue of sample selection bias. The addition of firms into the COMPUSTAT database universe is not a random process, hence, there is a sample selection issue that may bias our estimation results. As 
a robustness check, we use Heckman 2-stage procedure (Heckman, 1979) to correct for the selection bias. We report our results in table B1. Sample selection does not seem to affect our results.

\section{(TABLE B1 HERE)}

Second, we show that small firms have lower exposure to aggregate productivity risk than large firms. It is reasonable to believe that small firm have higher weight on new investment projects than larger firms; therefore our evidence on the lower risk exposure of small firms provides further support to our model specification. We consider the following regression:

$$
\Delta \log a_{i, t}^{j}=\xi_{0}^{j}+\xi_{0, i}^{j}+\phi^{j} \Delta \log A_{t}
$$

for $j=\{$ large, small $\}$, and apply it to large and small firm subgroups formed by the top and bottom $20 \%$ quantiles of firm size. We allow for a firm fixed effect through the term $\xi_{0, i}^{j}$. The coefficient $\phi^{j}$ denotes the exposure of individual firms' productivity growth to aggregate productivity risk. The regression results are presented in table B2. For large firms, $\phi$ is statistically significant and close to one, consistent with our model. For small firms, instead, $\phi$ is statistically indistinguishable from zero, again consistent with our model specification. These results also hold when we apply the Heckman's correction procedure (Panel B).

(TABLE B2 HERE) 
Table B 1: Exposure to Aggregate Risk by Firms' Age (II)

\begin{tabular}{lcc}
\hline \hline & \multicolumn{2}{c}{ With Fixed Effect } \\
\cline { 2 - 3 } Capital Share $\left(\alpha_{1}\right)$ & First Stage & Second Stage \\
& $0.339^{* * *}$ & \\
Labor Share $\left(\alpha_{2}\right)$ & $(0.005)$ & \\
& $0.524^{* * *}$ & \\
Age Effect $\left(\xi_{3}\right)$ & $(0.008)$ & $0.033^{* * *}$ \\
& & $(0.006)$ \\
$R^{2}$ & & 0.035 \\
No. of Firms & 0.59 & 17,970 \\
No. of Observations & 19,616 & 182,206 \\
\hline \hline
\end{tabular}

This table reports firms' risk exposure by age. The structure of this table is the same as Table 2 . We use Heckman (1979) two-stage procedure to correct for selection bias. We start by estimating a probit model explaining the decision of firms to exit the market or not, then include the inverse mills ratio (IMR) in the second stage regression. We use $* * *$ to indicate a p-value lower than 0.001 . 
Table B 2: Exposure to Aggregate Risk by Firms' Size

\begin{tabular}{|c|c|c|c|c|}
\hline \multicolumn{5}{|l|}{ Panel A: } \\
\hline & \multicolumn{2}{|c|}{ Small Firms Group } & \multicolumn{2}{|c|}{ Large Firms Group } \\
\hline & First Stage & Second Stage & First Stage & Second Stage \\
\hline \multirow[t]{2}{*}{ Capital Share $\left(\alpha_{1}\right)$} & $0.197^{* * *}$ & & $0.502^{* * *}$ & \\
\hline & $(0.011)$ & & $(0.011)$ & \\
\hline \multirow[t]{2}{*}{ Labor Share $\left(\alpha_{2}\right)$} & $0.546^{* * *}$ & & $0.366^{* * *}$ & \\
\hline & $(0.016)$ & & $(0.016)$ & \\
\hline \multirow[t]{2}{*}{ Aggregate Risk Exposure $(\phi)$} & & 0.348 & & $1.150^{* * *}$ \\
\hline & & $(0.285)$ & & $(0.087)$ \\
\hline$R^{2}$ & 0.284 & 0.031 & 0.626 & 0.027 \\
\hline No. of Firms & 8,052 & 5,753 & 3,092 & 2,971 \\
\hline No. of Observations & 37,449 & 26,300 & 41,678 & 37,667 \\
\hline \multicolumn{5}{|c|}{ Panel B: Correct for Selection Bias } \\
\hline \multirow{3}{*}{ Capital Share $\left(\alpha_{1}\right)$} & \multicolumn{2}{|c|}{ Small Firms Group } & \multicolumn{2}{|c|}{ Large Firms Group } \\
\hline & $0.193^{* * *}$ & & $0.481^{* * *}$ & \\
\hline & $(0.011)$ & & $(0.011)$ & \\
\hline \multirow[t]{2}{*}{ Labor Share $\left(\alpha_{2}\right)$} & $0.538^{* * *}$ & & $0.368^{* * *}$ & \\
\hline & $(0.016)$ & & $(0.016)$ & \\
\hline \multirow[t]{2}{*}{ Aggregate Risk Exposure $(\phi)$} & & 0.434 & & $0.918^{* * *}$ \\
\hline & & $(0.229)$ & & 0.092 \\
\hline$R^{2}$ & 0.282 & 0.034 & 0.575 & 0.025 \\
\hline No. of Firms & 7,780 & 5,457 & 3,087 & 2,785 \\
\hline No. of Observations & 35,293 & 24,515 & 39,071 & 35,085 \\
\hline
\end{tabular}

This table reports firms' risk exposure by size. For each group, the column under "First Stage" reports the statistics of the first stage regression. The column under "Second Stage" reports the statistics of the second stage regression, based on the equation (B.1) in Appendix B. Panel A and B report the results with/without correcting for selection bias through Heckman (1979) two-stage procedure, respectively. We use $* * *$ to indicate a p-value lower than 0.001 . 


\section{Appendix C: Measurement of Quantities in the Data and their Construc- tions in the Model}

1. Consumption $\left(C_{t}\right)$ : Per capita consumption data is from the National Income and Product Accounts (NIPA) annual data reported by the Bureau of Economic Analysis (BEA). It is constructed as the sum of consumption expenditures on nondurable goods and services (Table 1.1.5 Line 5 and 6 ) deflated by corresponding price deflators (Table 1.1.9 Line 5 and 6).

2. Physical Investment $\left(I_{t}\right)$ : Physical investment data is also from the National Income and Product Accounts (NIPA) annual data reported by the Bureau of Economic Analysis (BEA). We measure physical investment by fixed investment (Table 1.1.5 Line 8) less information processing equipment and software (Table 5.5.5 Line 3) deflated by its price deflator (Table 1.1.9 Line 8). Information processing equipment and software is interpreted as investment in intangible capital and is therefore substracted from fixed investment.

3. Measured Output $\left(Y_{M, t}\right)$ : The sum of total consumption and physical investment, that is, $C_{t}+I_{t}$. Note measured output differ from the actual output by $J_{t}$. In the data, we do not have accurate measure of $J_{t}$ for the long sample period (1929-2003) as we do for consumption and physical investment data. We therefore compare our model's implications on measured output with that in the data.

4. Intangible Investment $\left(J_{t}\right)$ : We follow the procedure in Corrado, Hulten, and Sichel (2006) to construct intangible investment in the post-war period in the data.

5. Projected Volatility of Market Return: We follow a two-step procedure. We use the multifactor productivity index for the private non-farm business sector from the Bureau of Labor Statistics (BLS) as a proxy for Total Factor Productivity, $A_{t}$ in the model. We first construct the estimates of the long-run components of productivity shocks $x_{t}$ using the Kalman filter. We then construct the projection of the return on the S\&P 500 index as in Equation (26) with $\Delta x_{t}$ replaced by its empirical estimates. We then measure the productivity-related volatility in the data according to the procedure described in Section $\mathrm{C}$ of the paper. Our results are robust to alternative ways of estimating the long-run component of the productivity shocks, since the measure of productivity-related volatility does not require accurate estimation of the long-run component, as explained in Section $\mathrm{C}$ of the paper.

In the model simulations, $x_{t}$ is perfectly observable, and the $R^{2}$ of the regression in (26) is essentially $100 \%$. We constructed estimates of $x_{t}$ using the realized productivity in the simulated data as we did in the data. We obtain very similar results by using estimates of $x_{t}$ instead of the true $x_{t}$ in the simulated data. 